\title{
Audiovisual Translation:A Critical Review on Sino-western Perspectives of Film Subtitle Translation
}

Junchen Zhang*

The Doctor of Applied Language Sciences Programme, The Hong Kong Polytechnic University, Hong Kong S.A.R., China

Corresponding Author: Junchen Zhang, E-mail: junchen.zhang@connect.polyu.hk

\section{ARTICLE INFO}

Article history

Received: December 07, 2017

Accepted: January 21, 2018

Published: January 31, 2018

Volume: 6 Issue: 1

Advance access: 2018

Conflicts of interest: None

Funding: None

\section{Key words:}

Audiovisual Translation (AVT),

Sino-western Perspective,

Film subtitle Translation,

Chinese wuxia Culture,

Social-cultural Elements

\begin{abstract}
The paper argues the development of audiovisual translation (mainly focuses on the strand of film subtitle translation) in the West and China. Firstly, the paper discusses film translation from the perspective of the West and critically reviews the achievements produced by western researchers. Secondly, the paper analyzes film translation from Chinese perspective and outlines its change and development in Mainland China. Thirdly, some major issues exited in film translation such as cultural problems, technical issues and translation strategies are analyzed. And in the fourth part, the paper takes a unique Chinese film genre, Chinese martial arts/wuxia film (中國武俠電 影), as a specific case to analyze and then further discuss the studies of film translation in the context of Chinese culture. The potential underexplored areas of translating Chinese martial arts film are also identified. Lastly, the paper argues the audiovisual translation from an inter- $/$ multi-disciplinary angle involving film study, social-cultural study, multimodal analysis and relevant linguistic approaches and then points out the potential future trends in audiovisual translation studies. In short, there are three significances in the research. The first one is making a comparative analysis to development path of film translation between Western side and China's side. The second is arguing the translation of Chinese wuxia film from a diachronic perspective and identifying existed research gaps. The last is pointing out the potential research trends based on the latest research progress.
\end{abstract}

\section{INTRODUCTION}

Over the past decades, with the development of cinema industry and audiovisual technologies, audiovisual translation or also called screen translation has increasingly attracted academia's attention. Although Karamitroglou (2000, p.10) ever pointed out that audiovisual translation does not share equivalent status with literature translation, one could not deny that its academic value is gradually becoming significant not only in pure academic study but also in practice.

Film subtitle translation, as one of emerging research strands of audiovisual translation, is also becoming more and more important in translation studies in the age of digitalization. Film subtitle translation in Western academic circle has been experienced a relatively long developing period while it has only a short time in Mainland China's academia due to China's political-historical issues. Even though, film subtitle translation in China still has some achievements. In the following sections, I will discuss film subtitle translation in Western perspective and then in China's perspective. Specific issues of in film subtitle translation will also be discussed which focus on cultural problems, technical constraints and strategies of translation. Moreover, in order to further discuss a concrete phenomenon of film subtitle translation in Chinese culture, Chinese martial arts film (also called Chi- nese wuxia film中國武俠電影), will be taken as a specific case to analyze. At last part, I will argue some issues about future studies in film subtitle translation based on the current research progress in the field of audiovisual translation.

With regard to the significance of the research, its contributions can be generally summarized as three aspects. First, the research compares the development of film subtitle translation between the West and Mainland China. By comparative analysis, it shows that western research scope is larger than China's in some extent. But, Chinese researchers are catching up with their international counterparts. Second, the study takes Chinese martial arts film as a case to argue that Chinese researchers can use unique national-cultural recourse to study audiovisual translation within the context of Chinese culture. Specifically, three potential gaps in translating Chinese martial arts film have been identified. The last one is that the study reports some latest developments in the area of audiovisual translation and points out that interdisciplinary or multidisciplinary approach is a major trend.

\section{FILM SUBTITLE TRANSLATION FROM WESTERN PERSPECTIVE}

Since film industry has been matured after developing over one hundred years in European countries, film translation 
studies grows very fast. Further, some academic associations have been established by European scholars and researchers for studying film and film translation in a few decades ago (Yu 2015, p.500). One of the most influential organizations is European Association for Studies in Screen Translation $\left(\right.$ ESIST $\left.^{1}\right)$ where regularly organizes international conferences on audiovisual translation and interpretation. In terms of film translation, it mainly contains three forms, which are subtitling, dubbing and film adaptation. Subtitling film is one of the most popular forms for audience watching foreign language films, because making subtitling is "faster, cheaper and technically simpler” (Yau 2014, p.493).

In regard to the concept of subtitling, according to Shuttleworth and Moira's (1997, p.161) definition, it is“the process of providing synchronized captions for film and television dialogue". It is admitted that subtitling is a kind of translation, no matter what it is intra-lingual or inter-lingual. Besides, for describing subtitle translation, Nedergaard-Larsen (1993, p.208237) stated that subtitle translation is a special language transfer type which is written text transferred from original spoken language text. In this definition, the transfer of language text form is the core of emphasis. But translating subtitle is not just simply transferring source languages into target languages, subtitle translator must carefully concern many complex parameters, such as synchronization, constrains of time and space, cultural-bound terms and audience reception and etc.,

Subtitling translation in audiovisual products (e.g. TV dramas, movies, video clips and etc.) have been investigated expensively by European scholars, such as Nedergaard-Larsen(1993), Guardini (1998), Gottlieb (2000), Karamitroglou (2000), Chaume (2004), Cronin (2009) and others. Many insightful ideas have been inspired the advancement of this discipline.

Nedergaard-Larsen (1993) categorized cultural problems in subtitling and argued some ideas about how to bridge the gap between different cultures when translating film. In Nedergaard-Larsen's (1993) view, film is not only an instrument of entertainment but a special scope for understanding exotic cultures (ibid.). Guardini (1998) explored the decision-making in film subtitling. In the paper of Decision-making in subtitling (1998), Guardini (1998) analyzed the advantages and characteristics of dubbing and subtitling in translating British films into Italian and pointed out the technical and textual constraints of subtitling. Practical examples and corresponded translating methods are also provided in Guardini's (1998) research. These kinds of researches enlighten film subtitle practitioners to use appropriate methods in their own translation practices according to specific translating situations. Different from Guardini (1998), Gottlieb (2000) studied subtitle translation from technical perspectives, for example, examining what time a subtitle should be appeared and how long it should last for. Also, one point needs to be note is that the space of subtitles should not bother audiences' attention when they appear on a film screen accompanied with shot (ibid.). In the aspect of film translation strategies, Karamitroglou (2000,

1 For detail information about the association of ESIST, please check its official website https://www.esist.org/ p.4) summarized four categories of strategies in translating films: 1) "subtitling”, 2) "dubbing (lip-sync)", 3) "narration" and 4) "free-commentary". Although the four categories give us a general framework to translating films, their limits are obvious which are difficult to meet the needs of translating all film types.

Moving to a wider scope of film translation studies, Cronin (2009) introduced a translation approach to movie study that inspired an interdisciplinary study of combining film study, translation and ideology behind films. Cronin's (ibid) research focuses on the translators' role in movies and further examines "the representation of intra-diegetic instances of translation" (Planchenault 2010, p.431). Additionally, in order to analyze film language further, Chaume (2004, p16- 22) identified a series of "signifying codes of film language", which include 1) "the linguistic code", 2) "the paralinguistic code", 3) "the musical and special effects code", 4) "the sound arrangement code", 5) "the iconographic code", 6) "photographic codes", 7) "the planning code", 8) "the mobility code", 9) "graphic codes" and 10) "syntactic codes". Chaume's (2004) typology of codes of film language provides a detail diagram to us better understanding how an audiovisual text organizes its visual meaning and how it construct its semantic structure. Moreover, taking into account the nature of audiovisual text, Taylor (2016, p.222236) proposed a multimodal analytical framework to analyze audiovisual texts which Italian film is an important audiovisual resource. By analyzing multimodal discourse of film, one of crucial concerns is "how translator can be made sensitive to the entire semiotic impact of a multimodal text" (ibid., p. 222). Thus, "semiotic impact" and "semiotic modalities", such as "visual frame", "visual images" and "kinesic action", in audiovisual text are important factors in Taylor's (ibid., p.229) work. Significantly, Taylor's (ibid. p.231) "mulitsemiotic referencing system" provides practitioners and researchers a framework to explore multimodal parameters of film.

In a word, western scholars have developed a set of approaches and frameworks to explore film subtitle translation. However, one has to admit that not all principles of film translation can guide translating activities. It is indeed very hard and even impossible to build a universal formulation to guide translators' practices in doing subtitle translation. Furthermore, many complex factors, such as target country's culture, traditions, audiences' ideology and manipulation of film producers, could also influence and constraint translator's decision-makings. The film translation is still developing. With the culture turn of translation studies in 1990s, it has drawn on knowledge and approaches from other social disciplines and towards to a direction of inter-/multi-disciplinary studies.

\section{FILM SUBTITLE TRANSLATION FROM CHINESE PERSPECTIVE}

Different from the developing path of film translation study in western academic community, Mainland China's film translation had been experienced a relatively slow pace since 1980 s. Prior to 1980 s, foreign films were mainly imported from Soviet Union and translated from Russian into Chinese. Only starting from 1980s, with the implementation of China's "reform and open up" policy, English films began to 
be imported by China's government. Since 1990s, with the largely increase number of English language movies imported into Mainland China's market, the film translation had started to attract much attention by Chinese scholars. But, film subtitle translation was not regarded as an academic study in Mainland China at that time. It was only regarded as a practical foreign language skill but not as a formal academic discipline for a relatively long period of time. It is obvious that film translation studies in Mainland China lags behind the western academia in a certain period.

In the late 1990s, some pioneering Chinese translation scholars proposed their views on studying audiovisual translation. In this period, Chinese researchers manly focused on translation principles and strategies in film and TV drama subtitle translation. Zhang (1998) examined several basic concepts and principles on audiovisual translation. He argued that there are five limits in translating audiovisual texts, which are 1) "the limits of dialogue number", 2) "the limits of actor's action", 3) "personification of film language", 4) "cultural references" and 5) "pun". His principles are concise and efficient, but they are just simple summarized from his experience and practice of subtitle translation which lack of systemic and theoretical research.

In addition to propose subtitling strategies, Qian (2000) pointed out that film translation would play an increasing significant role in China and he called on Chinese scholars and translators attach importance to it. In his paper, on one hand, he argued that the status of audiovisual translation was not noticed by Chinese scholars of translation studies, which showed that many universities in Mainland China did not have that major. On the other hand, he summarized five characteristics of film languages (e.g. listening, comprehensiveness, instantaneousness, popularity and without annotations) and proposed seven principles in film subtitling translation through his rich experience of TV drama subtitling translation. Indeed, his study has shed light on film subtitle translation in Mainland China, but does not form a systematic and theoretical framework.

Chang (2014, p.24) discussed the cultural differences in translating film subtitle from a perspective of intercultural communication. She investigated film translation products between China Mainland and Taiwan, making a comparative film translation studies across Taiwan Strait. Yu (2015) made a brief review and summary on film translation at home and abroad, and explored some technical constraints, features, and practicable translating methods in subtitling and dubbing in film translation. Other Chinese researches put emphasis on translation theories adopted in some specific film case analysis. For example, Ji and Song (2007) summarized the strategies of English subtitling translation in the film of Hero. Huang (2010) discussed Chinese-English subtitling translation from the principles of Faithfulness and Expressiveness. Zhang (2009), Yan (2010), Chen and Han (2013) explored subtitle translation from Skopos theory, Relevance theory and Adaptation-selection theory, respectively.

In recent studies, some Chinese translation scholars have integrated political-ideological study with audiovisual translation, providing some insightful ideas. For example, Jian
(2012) exploitedLefevere's (1992) rewriting theory to examine ideological elements and "poetics" (Lefevere 1992) in Hollywood blockbusters in Mainland China. He took the movie Mr. \& Mrs. Smith as case to analyze how to use translation strategies to balance political ideologies and traditional values when translating English subtitles into Chinese. One of important findings is that film translators tend to give more entertaining elements in translations because the nature of commercial film (Jian 2012, p.77). However, translators create more funny factors in their translations implying to add or rewrite contents from the original text, which is a kind of betraying to source text. Thus, loyalty to source text or jumping out source text is still an interesting debate. Another example is about English popular TV drama translation. Wang and Zhang (2016) used the TV drama, "House of Cards", as a case to study ideological manipulation in the process of translating the English version of American TV drama into Chinese subtitle version. Their research focuses on four levels. The first one is political metaphors behind the American political TV drama. The second one is Chinese translation of this TV drama and its release procedure in Mainland China. The third one is censorship of sensitive contents of "House of Cards" and the last one is why Chinese government allows the drama which contains political sensitive factors related to Chinese Communist Party to enter Chinese market. One of interesting opinions is that the reason why the second season of "House of Cards" could be released in Mainland China is that one of crucial leaders of Chinese Communist Party, Qishan Wang, had been given some positive comments on the TV drama (Wang and Zhang 2016, p. 14).

In short, based on the above literature survey, Chinese scholars' scope of research is relatively narrow over the past decades. Most of studies still remain in discussing strategies of subtitling translation, but one should note that some Chinese scholars have started to explore ideological issues behind audiovisual texts. In contrast, their western counterparts' research scope is broader that they not only explore specific translation methods in some specific films or video clips but also explore social-culture relations shown in audiovisual texts. Without doubt, the research of audiovisual translation is still developing and it has already achieved some progresses in Mainland China.

\section{THREE SPECIFIC ISSUES IN FILM SUBTITLE TRANSLATION}

In addition to review subtitling studies from the sides of the West and China, I will briefly discuss three major specific issues in film subtitle translation: 1) cultural-bound problems (Nedergaard-Larsen 1993, p.207-241), 2) technical constraints, and 3) translation strategies.

\section{Cultural References}

Cultural references in film subtitle translation are unavoidable, because film is also a product of a certain culture. Cronin (2009) argued the relations among culture, society, migration, national identity and globalization with interdisciplinary perspectives in the context of film and translation. He analyzed the effects of film translation in dealing with conflicts of culture 
and language. Other researchers concentrated on studying how to understand the hidden ideological factors through reading exotic culture (Asad 1986 \& Robinson 1997). The so called hidden things in foreign culture shown by movie are audiovisual factors that stimulate viewers' sense directly and simultaneously. In order to tackle culture-bound problems in film subtitle translation, Nedergaard-Larsen (1993, p.219) proposed six translation strategies, which are 1) "transfer/loan", 2) "direct translation", 3) "explicitation", 4) "paraphase", 5) "adaptation to TL-language" and 6) "omission". Although the six strategies can be used to deal with many general cultural problems, subtitle translator have to consider carefully according to specific cultural problems, because culture is untranslatable sometimes in some certain cultural context.

\section{Technical Limits}

Technical aspects of film subtitle translation are continuously concerned by some scholars. Subtitling translation has to consider time limitations, spatial limitations and layout (Karamitroglou 1998; Li 2001; Yan 2006; Yu 2013 et al). Generally, the duration of appearance of subtitle is really short, nearly 1 to 3 seconds along with one shot (ibid.). In order to maintain image clear, subtitle normally occupy two lines space in one picture (Yu 2013, p.9). Subtitle translation is constrained by time and space, so it is also called "constrained translation" (Diaz-Cintas 1999). Thus, the time and space in subtitling translation are main issues that translator needs to concern carefully.

\section{Translation Strategies}

Strategy for subtitle translation occupies a vital position in film translation studies. Many prestigious scholars have developed a series of principles based on their translating experiences and theoretical studies (Gottlieb 2001, Qian 2000, Li 2001, Yu 2013 et al.). Asimakoulas (2004, p.840) reported that "subtitles have to be concise and clear, because space and time restrictions are simultaneously at play". Nedergaard-Larsen (1993, p.219) summarized six methods in film and teleplay subtitle translation. These strategies aiming at over cultural barriers in subtitle translation can be summarized as "transfer or loan", "direct translation", "explicitation", "paraphrase”, "adaptation" and "omission". Li (2001, p.39) and Yu (2013, p.59-62) also developed four principles for translating movie subtitle based on the features and constrains of film subtitle: 1) "standardization", 2) "simplification/condensation", 3) "reductive paraphrasing" and 4) "omission/deletion". Strategies in translating audiovisual texts should be used flexibly and appropriately according to specific conditions, which mean subtitle translator should not totally rely on principles and methods of translation in textbooks.

\section{CRITICAL REVIEW ON TRANSLATING CHINESE MARTIAL ARTS/WUXIA FILM}

In the above sections, I have discussed the perspectives from the West and China, and also analyzed three concrete issues of film subtitle translation. Now it is time to move on to a more concrete and unique area in audiovisual translation in
Chinese context, which is translation of Chinese martial arts film. Chinese "martial arts" film is also called "wuxia" (武 俠) film in the context of Chinese culture if we do not pursue to distinguish too much detail differences. By taking Chinese wuxia film as a case study, one of purposes is to argue specific research gaps in Chinese film subtitle translation, which may not only exist in Chinese wuxia film but also in other film genres.

Chinese wuxia film is one of Chinese national and cultural icons. The concept of "wuxia" can be traced back to Han Feizi's (韓非子) thought of 2000 years ago around 300 BC in ancient China. Chinese "wuxia" can be literally translated into "martial arts hero" or "chivalry knight" in English. “Wu" (武) refers to "wushu" (武術) that is "martial arts" in its English counterpart, which is a fighting sport with strong Chinese characteristics and nationalism color, meanwhile "Xia" (俠) refers to "hero" or "knight chivalry" in English (Lu et al. 2014). But there are not completely equivalent English words to render the connotation of Chinese "wuxia".

Chinese wuxia film, as one of sub-genre of martial arts film, is a unique film type that combines classical Chinese elements, such as, Chinese kung fu, swordplay fighting and Chinese historical events. In addition, classic Chinese philosophies are important elements that usually go through the storyline in some Chinese wuxia films. As a typical and the oldest genre in Chinese cinema (Teo 2009), the wuxia film is very popular in Chinese speaking world. It is regarded as a common language of at home and oversea Chinese, which even could be said that "where there is Chinese community where there is wuxia culture" (Chen 1994). According to Chen (1994), wuxia contains three fundamental elements, "Wu" (kungfu/fighting 武), "Xia" (hero 俠) and "Chuanqi" (legend 傳奇). The three elements construct a charismatic hero legendary story evoking Chinese viewer's resonation and in this way to enhance cultural and national identity in Chinese speaking world. So, Chinese wuxia film has become a significant popular culture phenomenon and played a key role in shaping Chinese cultural and national identity.

Since China implemented the policy of "reform and open up" in 1980 s, a large number of western movies, especially Hollywood English blockbusters, had been translated into Chinese and distributed into China's cinematic market due to "looser control over the import of foreign movies" (Qian 2004, p.54). Correspondingly, Chinese films also tried to export to oversea market. In this circumstance, Chinese wuxia film as a unique genre of Chinese cinema has special advantages to enter oversea market. The first advantage is mysterious oriental characteristics with Chinese style. The second one is the fantastic kung fu and swordplay fighting. The last one is unique visual representations with Chinese ancient flavor. However, the language and dialogue in Chinese wuxia film are very implicit that are related to Chinese ancient thoughts (e.g. Confucianism and Daoism), slangs and idioms which are difficult to understand and appreciate from the angle of English speaking audiences who do not possess knowledge of Chinese culture. Therefore, when translating language of Chinese wuxia film into English, strategies of translation should be applied according to different specific 
purposes meanwhile the original Chinese flavor should be kept and transmitted to target language and target culture maximally.

In the context of film translation studies in China, previous researches mainly focus on translation strategies and principles (Li 2001, Qian 2004, Yang 2006, Yu 2014 et al.), cultural transfer (Li 2005, Chai 2001, Wang 2009 et al.) and translation theories applicable in subtitling (Huang 2010). Differently, Zhou (2011, p. 80-83) discussed the poetics in Chinese wuxia films and the transfer of narrative tactics in Chinese wuxia films made by An Lee, Karwai Wong and John Woo, respectively. From the angle of soft power, Christablelle (2013) examined the cultural influence of Chinese martial arts film in Singapore and studies the spreading of soft power of Chinese culture in Singapore using the ethnographic method. There are also some researches focusing on technical level of language transfer between Chinese and English in translating wuxia film. For the field of English translation in Chinese wuxia film, there are still not enough academic studies. Based on the previous discussion, three gaps can be identified preliminarily.

The first gap is that the research of Chinese wuxia film is usually neglected by Chinese researchers to some extent. On one hand, Chinese scholars consider subtitling and dubbing audiovisual materials are not very academic so "nearly no one discusses and concerns about this area" (Li 2001, p.38). On the other hand, Chinese wuxia film that is original from wuxia novel which is a type of popular culture and is not regarded as a true literature in a long time. So, this leads to Chinese wuxia film as one of branches of film genre does not become an academic hot spot in mainstream translation academic study in Mainland China.

Furthermore, on the one hand, it should be noted that Chinese wuxia film is a Chinese national film tradition that is full of typical Chinese characteristics. On the other hand, its storyline contains Chinese classic thoughts and philosophies that are exotic cultural elements for non-Chinese cultural world. Specifically speaking, it is embedded with ancient Chinese cultural ideology. Therefore, it can be said that when it comes to meet the Chinese wuxia cultural context, translation is intertwined with cultural ideology, because "the relationship between ideology and translation is multifarious. Any translation may be reproduced as ideological since the choice of source text and the use of which the subsequent target text is determined by the interest, aims and objectives of social agents. But ideological aspects can also be determined with a text itself, both at the lexical and grammatical level" (Schäffner 2003, p.23-42). However, many previous studies did not realize that even a Chinese wuxia film looks like a pure commercial or artistic movie, it still exists ideological manipulation. So, that is the second gap which needs to be filled.

Thirdly, as a nationalism film genre, Chinese wuxia film has distinguished cultural identity with other film genres. However, the unique Chinese cultural information may be lost in some part when it is translated into English in that there is not a language equivalent with another language totally. Therefore, lacking of systematically investigating cultural identity and do not distinguish which parts of Chinese wuxia culture are translatable or untranslatable are contributed to the third research gap.

In the age of multimedia and globalization, film plays a significant role in transmitting one country's culture and ideology to another one. Chinese wuxia film as Chinese nationalism cultural figure is unconsciously disseminating Chinese culture ideology. Its unique film language is typical Chinese style embedded different cultural references which are very difficult to fully translate into English. Also, the translation of film subtitle is visible in that viewers watch a Chinese style movie but dialogue is English, which is also a worth research point.

\section{NEW DEVELOPMENT OF AUDIOVISUAL TRANSLATION}

As one of strands in translation studies, film subtitle translation experienced a change accompanied with the cultural turn of translation in 1990s. According to Yau (2014, p.496), scholars of audiovisual translation have turned their research directions from usual issues, such as technical perspectives and translation strategies, into "issues of otherness, power relations, and contexts in which dubbing and subtitling are produced and received" (ibid.). In addition, "fansubbing" or so called "the subtitling of foreign films by fans" (ibid.) is becoming a trend along with the rapid development of Internet. Also, according to Wang and Zhang (2017), fansubbing translation group in China has been developed quite fast over the past decade with the advancement of social media and development of digital communication technology. Based on their research, the appearance of Chinese fansubbing networks is "a representation of a process of technology democratization" (ibid., p.301).

In Mainland China, there are many subtitle translation groups that are consist of film fans, English TV drama fans and Japanese cartoon fans who master two languages, such as Chinese \& English and Chinese \& Japanese. They translate English films/TV dramas or Japanese animates into Chinese and share them through Internet virtual communities. Most of the subtitle translation groups are non-profits. They making subtitles translation totally relies on their interest and passion. In this new phenomenon that appeared with the advancement of internet and digitalization, Perez-Gonzalez (2006, p.267268) stated that fansubbers possess "uniquely multifarious capacity as patrons, producers, distributors and viewers of the subtitled product". However, many members of these subtitling translation groups in Mainland China are amateurs who may not have professional translation training, so the translation quality of subtitle cannot be guaranteed; and usually there are many obvious errors, such as omission, distortion, and alteration of original meanings, which is easy to cause target audiences' misunderstand. Therefore, how to improve the translation quality of subtitle is a concern in the future.

Additionally, there is one point that needs to be noted. Since audiovisual translation related with images, sounds, visual symbols, technologies and even social power relations in a large context, a multimodal approach is also adopted by researchers to analyze film language, structure of visual semantics, social-cultural relations (Bateman \& Schmidt 
2012). Thus, using multimodal analytical framework to explore subtitle translation is one of important directions in future research of audiovisual translation studies (Taylor 2013/2016). At the same time, one should also note that although multimodal approach to audiovisual translation is an important direction, there are others that need to be concerned. In recent outputs of audiovisual translation, an inter/multi-disciplinary approach is emerging. For example, Burchardt and Lommel et al. (2016) have investigated the "machine translation quality" in audiovisual materials; Braun (2016) has proposed "a cognitive-pragmatic model" including "Relevance theory" and "Mental Model Theory" to study audiovisual text. What's more, according to Kruger (2016), psycholinguistic approaches, e.g. Functional Magnetic Resonance Imaging (fMRI) and eye-tracking were also introduced into study language process of audiovisual translation. In short, the future study of audiovisual translation (subtitling and dubbing) will enter the stage of inter- or multi- disciplinary study.

\section{CONCLUSION}

In this paper, the studies of film subtitle translation from Western side and China's side have been explored from the major three perspectives, which are concepts of subtitling, constraints of subtitling and strategies of subtitling translation. Generally, western researchers have a broader research span that involves linguistic, non-linguistic, semiotic, social and cultural perspectives and etc., whereas China's scholars prefer to study translation strategies and methods in film subtitle by using theories of translation which means that the scope of China's film subtitle translation is relatively narrow in some extent. But, in recent years, some Chinese scholars (e.g. Jian 2012; Wang and Zhang 2016) have started to do research linking film translation with social-ideological approaches, which implies that the scope of film translation in Chinese academic community has started to expand gradually.

In addition to exploring the different paths of development in the West and China, three specific issues of film subtitle translation also have been briefly discussed, i.e. cultural references, technical constraints and translation strategies. Beside general analysis to film subtitle translation between the Western side and Chinese side, the paper further takes a unique Chinese film genre, Chinese martial arts film, as a specific case of analysis to argue specific issues of film subtitle translation in Chinese context. Furthermore, the study has identified three potential underexplored areas in Chinese martial arts film translation. Based on the previous discussions, in the last section, the paper argues potential new trends in the field. In this part, some innovative approaches and new paradigms such as "multimodal and multisemiotic approach" (Taylor 2013/2016), "cognitive-pragmatic model" (Braun 2016) and "psycholinguistic approach" (Kruger 2016), are introduced into audiovisual translation studies. Overall, the paper concludes that the future development of film translation or audiovisual translation in a general context will be toward to a stage of inter- or multi- disciplinary study.

\section{REFERENCES}

Asimakoulas, D. (2004). Towards a Model of Describing Humour Translation: A Case Study of the Greek Subtitled Versions of Airplane! and Naked Gun!. Meta: Journal des traducteurs/Meta: Translators' Journal, vol. 49. No. 4. pp. 822-842.

Bermann, S. (2014). Translation and Film: Dubbing, Subtitling, Adaptation, and Remaking. In A Companion to Translation Studies(pp. 492-503). Oxford, UK: John Wiley \& Sons.

Bateman, J., \& Schmidt, K. (2012). Multimodal film analysis: How films mean (Routledge studies in multimodality; 5). New York: Routledge.

Burchardt, A., Lommel, A., Bywood, L., Harris, K., \& Popović, M. (2016). Machine translation quality in an audiovisual context. Target. International Journal of Translation Studies, 28(2), 206-221.

Chen, M. (1994). Talking about Chinese martial arts movies. Contemporary Cinema. Vol. 4. pp. 68-75.

Chaume, F. (2004). Film Studies and Translation Studies: Two Disciplines at Stake in Audiovisual Translation. Meta, 49(1), 12-24. doi:10.7202/009016ar

Cronin, M. (2009). Translation goes to the Movies. London and New York: Routledge.

Chang, G. C. (2014). Film Translation in Chinese Mainland and Taiwan: A Theoretical Exploration of Intercultural Communication across the Strait. International Journal of Comparative Literature and Translation Studies, 2 (3), 24-35.

Chen, M. \& Han, J. (2013). On Linda Jaivin's subtitle translation of Hero from the perspective of translation as adaptation and selection. Journal of Hefei University of Technology (Social Sciences). Vol. 27. No. 2. Pp.98-102.

Chai, M. (2001). Reconstruction, modification and nonequivalence of cultural image in film translation. Academic Journal of Suzhou University (Philosophy and Social Science). No. 4. pp. 91-94.

Christablelle, S. H. (2013). Chinese martial arts films and China's soft power in Singapore. China Media Research, 9(2), 11-23.

Díaz-Cintas, J. (1999). Dubbing or subtitling: The eternal dilemma. Perspectives: Studies in Translatology, 7(1), 31-40.

Guardini, P. (1998). Decision-making in subtitling. Perspectives, Studies in Translatology, 6(1), 91-112.

Gottileb, H. (1998). Subtitling. in Routledge Encyclopedia of Translaiton Studies, (Ed.). by Mona Baker, pp. 243249. London and New York: Routledge.

Huang, X. (2010). On "Faithfulness" and "Expressiveness" in subtitle translation of Chinese films: a perspective of receptive aesthetics. Journal of Zhejiang Normal University. Vol.35. No.2 pp. 61-64.

Holmes, J. (1988). Translated! Papers on literary translation and translation studies (Approaches to translation studies; v.7). Amsterdam, Netherlands: Rodopi.

Ji. F. \& Song. J. (2007). An exploration to English subtitle translation of Hero. Shanghai Journal of Translators. No.2 pp. 77-79. 
Jian, L. I. (2012). Ideological and Aesthetic Constraints on Audio-visual Translation: Mr. \& Mrs. Smith in Chinese. Intercultural Communication Studies, 21(2).

Karamitroglou, F. (2000). Towards a Methodology for the Investigation of Norms in Audiovisual Translation. Amsterdam: Rodopi.

Kruger, J. L. (2016). Psycholinguistics and audiovisual translation. Target. International Journal of Translation Studies, 28(2), 276-287.

Lefevere, A. (1992). Translation, rewriting, and the manipulation of literary fame. London \& New York: Routledge.

Li, Y. (2005). On the translation of film scripts and TV drama scripts from cultural translation perspective. Journal of Hunan University (Social Science). Vol. 19, No.3 pp. 81-84.

Lu Z., Qi Z. \& Fan, H. (2014) Projecting the 'Chineseness': Nationalism, Identity and Chinese Martial Arts Films, The International Journal of the History of Sport, 31:3, pp. 320-335.

Montse, C. \& Zabalbeascoa, P. (2011). Language variation in source texts and their translations: The case of L3 in film translation. Target. 23(1), 113-130.

Nedergaard-Larsen, B. (1993). Culture-Bound Problems in Subtitling. Perspectives: Studies in Translatology, Vol.2, 207-241.

Perez-González, L. (2006). Fansubbing Anime: Insights into the 'Butterfly Effects' of Globalisation on Audiovisual Translation. Perspectives, 14(4), 267-268.

Planchenault, G., \& Cronin, M. (2010). Translation goes to the movies. Language in Society, 39(3), 431.

Qian, S. (2000). Film Translation: An increasing important area in Translation Studies. Chinese Translators Journal. Vol.1. pp. 61-65.

Qian, S. (2004). The Present Status of Screen Translation in China. Meta, 49(1), pp.52-58. doi:10.7202/009019ar.

Robinson, D. (1997). Translation and Empire. Manchester: St. Jerome Publishing.

Shuttleworth, M. \& Moira C. 1997. Dictionary of translation studies. Manchester: St Jerome Publishing.

Schäffner, C. (2003). Third Ways and new centres - ideological unity or difference? In M. Calzada Pérez (Ed.), Ap- ropos of ideology: Translation studies on ideology - ideologies in translation studies. pp. 23-41. Manchester: St Jerome Publishing.

Teo, S. (2009). Chinese Martial Arts Cinema: The Wuxia Tradition. Edinburgh University Press.

Taylor, C. J. (2013). Multimodality and audiovisual translation. Handbook of Translation Studies, 4, 98.

Taylor, C. (2016). The multimodal approach in audiovisual translation. Target. International Journal of Translation Studies, 28(2), 222-236.

Wang, D. \& Zhang, X. (2016). Ideological Manipulation of Controversial Information: The Unusual Case of the Chinese-subtitled Version of House of Cards. Altre Modernità - Other Modernities, 2016: Numero Speciale, 1-20. DOI: $10.13130 / 2035-7680 / 6845$

Wang, D., \& Zhang, X. (2017). Fansubbing in China. Target. International Journal of Translation Studies, 29(2), 301-318.

Wang, N. (2009). Deconstruction, postcolonial and cultural translation-A case study on Venuti's translation theory. Foreign Languages and Teaching. Serial no. 241. No. 4. pp. 51-56.

Yu, H. (2015). Film translation in China: Features and technical constraints of dubbing and subtitling English into Chinese. Babel, 61(4), 493-510.

Yau, W.-P. (2014) Translation and Film: Dubbing, Subtitling, Adaptation, and Remaking, in A Companion to Translation Studies (eds S. Bermann and C. Porter), pp. 492503. John Wiley \& Sons, Ltd, Oxford, UK

Yang, Y. (2006). A Review of the Movie Subtitling Translation. Journal of Southwest Jiaotong University (Social Sciences). Vol.7, No. 4. pp. 93-97.

Zhang, Q. (2009). Skopos theory and its application to subtitle translation of audio-visual products. Journal of Xian Eurasia University, Vol,(1):pp. 73-78.

Zhang, C. (1998). An Introduce to Audiovisual Translation. Chinese Translators Journal. Vol. (2) pp. 50-54.

Zhou, X. Jiang, S. \& Qiu, L. (2011). On Chinese languages cinema poetics. Journal of Xiangtan University (Philosophy and Social Sciences). Vol. 35, No. 6. pp. 80-83. 